\title{
Téoros
}

Revue de recherche en tourisme

\section{Le tourisme et le développement durable des grands fleuves}

\section{Marc Laplante}

Volume 11, numéro 3, octobre 1992

Fleuves, civilisations et tourisme

URI : https://id.erudit.org/iderudit/1078032ar

DOI : https://doi.org/10.7202/1078032ar

Aller au sommaire du numéro

Éditeur(s)

Université du Québec à Montréal

ISSN

0712-8657 (imprimé)

1923-2705 (numérique)

Découvrir la revue

Citer ce document

Laplante, M. (1992). Le tourisme et le développement durable des grands fleuves. Téoros, 11(3), 2-2. https://doi.org/10.7202/1078032ar d'utilisation que vous pouvez consulter en ligne.

https://apropos.erudit.org/fr/usagers/politique-dutilisation/ 


\section{Présentation \\ Le tourisme et le développement durable des grands fleuves}

Marc Laplante

La revue Téoros est déjà présente à plusieurs rencontres d'ici et d'ailleurs quand elles abordent la situation ou l'avenir du tourisme. Elle est parfois aussi invitée à faire un peu plus. Par exemple, quand un comités'est constitué pour tenirà Montréal, en 1992. un Colloque international sur le tourisme et le développement durable des grands fleuves, Téoros a reçu le mandat de préparer des documents pour soutenir les travaux du Colloque et pour en diffuserles résultats.

Le contenu du présent numéro a été préparé au printemps 1992 pour favoriser les discussions en atelier lors du Colloque international Fleuves et planète qui devait se tenir à Montréal le 31 mai et les 1, 2 et 3 juin; ce contenu serait alors paru dans notre nouvelle collection: Colloques et congrès. La rencontre du printemps dernier ayant été reportée aux 13,14 et 15 octobre, ce contenu forme maintenant l'essentiel du numéro régulier de la revue de l'automne 1992.

Je m'empresse, en premier lieu, de souhaiter aux participantes et participants du Colloque Fleuves et planète le meilleur des séjours à Montréal et au Québec et de fructueux échanges entre toutes ces personnes qui ont à coeur la qualité des environnements naturel et culturel, la protection et la mise en valeur des grands fleuves du monde - axes majeurs de civilisation - et le tourisme.

À nos lecteurs réguliers, il me faut préciser que le présentnuméro reflète en partie cequi futsa première raison d'être: un document scientifique de soutien à un colloque international. Conséquemment, nous avons d'abord procédé à un appel international de textes et les articles quiparaissent dans ces pages ont été sélectionnés par un jury composé de chercheurs et d'universitaires; chaque texte ou presque est présenté dans l'une des deux langues officielles du Colloque, suivi d'un résumé dans l'autre langue; les articles sont généralementassezcourts carils doivent servir souvent d'amorce aux discussions dans les ateliers; nous avions demandé aux auteurs des textes courts mais contenant plusieurs aspects capables de stimuler les échanges; enfin, le tourisme n'est pas le seulsujet de ce numéro qui traite aussid'écologie, de gestion, de sciences et techniques, etc. Le développementdurable des fleuves est un processus complexe mais il faut souligner que le tourisme est introduit dans les travaux de ce Colloque comme un desfacteurs de développementdurable. Les relations entre l'environnement et le tourisme semblent avoir trouvé, avecle tourisme fluvial, un courant favorable... 